\title{
Bactericidal and Smear Layer Removal Efficacy of Herbal Alternatives Against Enterococcus Faecalis Dentinal Biofilm - An ex-vivo Study
}

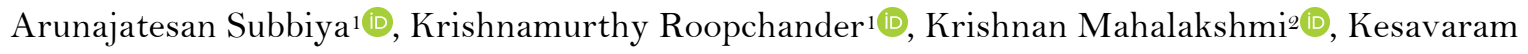 \\ Padmavathy2(10, Paramasivam Vivekanandan ${ }^{10}$
}

${ }^{1}$ Department of Conservative Dentistry, Sree Balaji Dental College and Hospital, Bharath Institute of Higher Education and Research, Chennai, Tamil Nadu, India.

2Department of Microbiology, Sree Balaji Dental College and Hospital, Research Lab for Oral-Systemic Health, Bharath Institute of Higher Education and Research, Chennai, Tamil Nadu, India.

Author to whom correspondence should be addressed: Krishnan Mahalakshmi, Professor \& Head, Department of Microbiology, Sree Balaji Dental College and Hospital, Research Lab for Oral-Systemic Health, Bharath Institute of Higher Education and Research, Chennai, 600100, Tamil Nadu, India. Phone: +91 9444184403. E-mail: kmagvenkat@gmail.com.

Academic Editors: Alessandro Leite Cavalcanti and Wilton Wilney Nascimento Padilha

Received: 24 December 2019 / Accepted: 23 April 2020 / Published: 04 May 2020

How to cite this article: Subbiya A, Roopchander K, Mahalakshmi K, Padmavathy K, Vivekanandan P. Bactericidal and smear layer removal efficacy of herbal alternatives against Enterococcus faecalis dentinal biofilm - an ex-vivo study. Pesqui Bras Odontopediatria Clín Integr. 2020; 20:e5475. https://doi.org/10.1590/pboci.2020.076

\begin{abstract}
Objective: To assess the antibacterial and smear layer removal ability of Trigonella foenum, Syzygium cumini, Terminalia chebula seed extracts against E. faecalis dentinal biofilm. Material and Methods: Agar well diffusion, micro broth dilution assay and time-kill curve assay were performed to determine the antibacterial activity. The ability of the herbal extracts to remove the smear layer on the root canal surface was assessed by scanning electron microscopy. Results: Antibacterial activity was observed for the extracts of S. cumini and $T$. chebula on E. faecalis dentinal biofilm and its planktonic counterparts. The smear layer was efficiently removed by the seed extracts of $T$. chebula alone. Seed extracts of $T$. foenum neither possessed antibacterial effect nor smear layer removal ability. Conclusion: The extracts of $T$. chebula seeds may replace conventional irrigant due to its antibacterial properties and smear layer removing the ability. The extracts of $S$. cumini may be used as an intracanal medicament as it exhibited a bactericidal effect against the $E$. faecalis dentinal biofilm following 18 hours of incubation.
\end{abstract}

Keywords: Endodontics; Root Canal Therapy; Plant Preparations; Microscopy, Electron, Scanning. 


\section{Introduction}

Enterococcus faecalis, gram-positive facultative anaerobic cocci, is rarely seen in primary infection but very commonly present in secondary infection and causes endodontic failure. Its prevalence ranges from $24 \%$ to $77 \%$ in root canal failed teeth [1]. The biofilm formation of $E$. faecalis can impede its elimination when using conventional irrigating solutions [2]. They also invade the dentinal tubules and are more resistant to intracanal medicaments during endodontic treatment [3]. Enterococci possess a number of virulence factors that permit adherence to host cells and extracellular matrix, facilitate tissue invasion, effect immunomodulation, cause toxin-mediated damage and withstands harsh environment [4].

The success of root canal therapy depends on the quality of the instrumentation, irrigation, disinfection and three-dimensional obturation of root canals [5]. Thirty-five percent of the canal system is left untouched by endodontic instruments [6]. The removal of vital and necrotic pulp tissue, microorganisms and their toxins, along with the smear layer, is achieved by cleaning and shaping [7]. Instrumentation with adequate irrigation is necessary to complete the cleaning process and reduce the microbial load within the root canal system. The most commonly used irrigants, which possess antimicrobial properties, include sodium hypochlorite $(\mathrm{NaOCl})$ and chlorhexidine [8].

$\mathrm{NaOCl}$ is used in the treatment of root canals with pulp necrosis because of its tissue dissolution and antimicrobial properties. $5.25 \% \mathrm{NaOCl}$ has been reported to be significantly effective against $E$. faecalis biofilm [9]. When $\mathrm{NaOCl}(5.25 \%)$ is used against E. faecalis, the bacterial burden was reduced rapidly, but most of the teeth were colonized again by 48 hours post-irrigation [10]. In addition, $\mathrm{NaOCl}$ has cytotoxic effects that can cause irritation and necrosis of periapical tissues [11,12].

Chlorhexidine (2\%) destroys E. faecalis planktonic cells, but several authors have reported the failure of $2 \%$ chlorhexidine to disrupt E. faecalis in biofilm form [5]. Chlorhexidine also results in rare side effects, such as desquamative gingivitis, discoloration of the teeth or dysgeusia (distorted taste) [13]. The most desirable endodontic irrigant should possess antimicrobial effect with minimal toxicity [14].

Trigonella foenum, commonly known as fenugreek belonging to the family Leguminosae, is a widely grown plant in India, Egypt, and Middle East countries [15]. Fenugreek seeds are useful for tuberculosis, diabetes, atherosclerosis, constipation, high cholesterol, hypertriglyceridemia and externally it is used as a poultice for abscesses, boils, carbuncles, etc. [16]. The seeds of the fenugreek herb possess toxic oils, and other bioactive constituents of the fenugreek seed include volatile oils and alkaloids, have been shown to be toxic to bacteria, parasites and fungi [17].

Syzygium cumini, popularly called as 'jamun' is an evergreen plant originally from Indonesia and India, belongs to the Myrtaceae family. It has antibacterial activity against Escherichia coli, Pseudomonas aeruginosa, Staphylococcus aureus and Bacillus subtilis [18]. The bark has anti-inflammatory activity and used in India for anemia, antibiotic activity, asthma, bronchitis. Juice of this plant is used for gingivitis and also against diarrhea and fever [19].

The plants of genus Terminalia, comprising of 250 species, are widely distributed in tropical areas of the world [20]. Fruits of Terminalia chebula Retzius (T. chebula Retz.) (Combretaceae), commonly known as black Myroblans in English and Harad in Hindi, indigenous in Pakistan and India among many Asian and African countries. It is popular folk medicine, which can be used against dental caries as it possesses antimicrobial action towards Streptococcus mutans and Staphylococcus aureus [21].

Drawbacks of conventional irrigants, side effects of synthetic drugs and increased antibiotic resistance have encouraged the researchers to look for herbal alternatives. The present study was chosen 
to assess the antibacterial activity and smear layer removal of S. cumini, T. chebula and T. foenum seed extracts against E. faecalis dentinal biofilm.

\section{Material and Methods}

Bacteria and Herbal Extracts

Antibacterial assay was carried out against E. faecalis culture isolated from retreated root canal. E. faecalis was isolated from clinical samples of root canal retreatment. Species identification of E. faecalis was carried out using standard microbiological methods [22]. E. faecalis ATCC 29212 was used as control.

Methanolic extracts of T. foenum, S. cumini and T. chebula seed powders were obtained by continuous hot percolation method using soxhlet apparatus. The extracts were concentrated and dried under reduced pressure. The stock solutions of the methanol free extracts were prepared in $10 \%$ dimethyl sulfoxide (DMSO) (S D Fine-Chem Limited, Mumbai, India). Agar well diffusion assay was performed to assess the efficacy of the herbal extracts. Ten microliters of $2 \%$ chlorhexidine (Asep-RC) and $5 \% \mathrm{NaOCl}$ (Prime Dental Products Pvt Ltd, Bhiwandi, India) were placed on sterile discs (HiMedia Laboratories Pvt Ltd, Mumbai, India) for the assay. DMSO (10\%) was also assayed to check if they showed any significant zone of inhibition. Vancomycin (30 $\mu \mathrm{g}$ ) (HiMedia Laboratories Pvt Ltd, Mumbai, India) was used to compare the antibacterial efficacy of the herbal extracts. The assay was done in triplicate. As the herbal extracts demonstrated promising results on planktonic counterparts of E. faecalis, the assay was further extended to three weeks in vitro biofilm formed on tooth dentin surface. Broth microdilution assay was performed to determine the minimum inhibitory concentration (MIC) and minimum bactericidal concentration (MBC) of the different herbal extracts.

\section{Biofilm Formation on the Root Canal}

The study was approved by the Institutional ethics committee, Sree Balaji Dental College and Hospital. Extracted single-rooted human mandibular premolars with fully formed apices were used. The tooth samples for biofilm formation were prepared and sterilized as per previous protocol [23]. E. faecalis culture was prepared in Mueller-Hinton Broth (MHB) and the turbidity was adjusted to 0.5 McFarland standards to obtain a cell density of $1.5 \times 10^{8}$ cells $/ \mathrm{mL}$. Tooth samples were divided into five groups, and each group comprised of five tooth samples. The broth culture was dispensed into the tissue culture plates (Zellkuthur, test plate 24 Europe / Switzerland) containing gamma sterilized tooth samples at a volume of $2 \mathrm{~mL} /$ well. The culture plates were incubated at $37^{\circ} \mathrm{C}$ for six weeks. To avoid nutrition depletion and accumulation of toxic end products, every alternate day, the media was replaced with sterile MHB. At the end of sixth week, Gram stain was done to check the purity of the culture.

Time Kill Assay on Six Week Biofilm

As the antibacterial activity was not shown by $T$. foenum, at the end of the sixth week, time-kill assay was performed for $S$. cumini and $T$. chebula seed extracts. The tooth samples were exposed to the methanolic extracts of $S$. cumini and $T$. chebula by immersing the samples to the respective test solutions. The concentration of the test solutions used for 6-week biofilm was six times the MIC valve. The colonyforming units (CFU) were determined after exposure to the test solutions at every 15 minutes time interval (o mins, 15 mins, 30 mins, 45 mins and 60 mins). The biofilm formed on the dentinal canal was removed using a sterile blade and transferred into Eppendorf microcentrifuge tubes containing $1 \mathrm{~mL}$ of sterile MHB [23]. The tubes were vortexed for 30 seconds. The spread plate method of inoculation was performed on the Mueller Hinton Agar plates with ten microlitres of the broth. The plates were incubated 
at $37^{\circ} \mathrm{C}$ for 24 hours. Following incubation, the colonies were counted with the help of a digital colony counter. The time-kill curve was plotted to assay time versus CFU/mL.

\section{Scanning Electron Microscopy (SEM) Analysis}

The six-week biofilm formed tooth samples were fixed with $10 \%$ formalin to assess the biofilm formation by SEM at 2000x magnification. The canal area of the tooth samples treated with the test solutions was observed under SEM to find out any dentinal changes and smear layer removal. Gold sputtering was done by mounting the samples on vacuum dried and gold-coated (Auto fine coater JOEL JFC-1600, JEOL Ltd, Tokyo, Japan) copper stub. The gold-sputtered samples were then examined under SEM (JOEL JSM-5610LV, JEOL Ltd, Tokyo, Japan) at 20kv. The photomicrographs of the canal area for observing smear layer removal was obtained at 5000x magnification.

\section{Statistical Analysis}

Statistical Analysis was performed using One-Way Anova (IBM SPSS, version 18, IBM Corp., Armonk, NY, USA) test to evaluate the significance of antibacterial efficacy among ATCC and clinical isolate of E. faecalis. Tukey's test (post hoc test) was used to compare between groups. P-value $<0.05$ was considered significant.

\section{Results}

Table 1 shows the results of agar well diffusion assay for E. faecalis ATCC and clinical isolate. The test group B showed a very high zone of inhibition for $50 \mathrm{mg}$ compared to $\mathrm{C}$ and $\mathrm{A}$. The test Group A (T. foenum) showed no inhibition for $50 \mathrm{mg}$ both on ATCC and clinical isolate. The zone of inhibition for Group B ( $T$. chebula) was high compared to vancomycin (30 $\mu \mathrm{g})$. Statistical analysis showed significance for the antibacterial activity of $T$. chebula $(\mathrm{p}=0.003)$ and $S$. cumini $(\mathrm{p}=0.015)$. The zone of inhibition was slightly high against clinical isolate compared to ATCC strain for Group C $(S$. cumini) and $2 \%$ chlorhexidine. No such difference was observed for Group B. It is clearly evident from the results that the clinical isolate of E. faecalis were more susceptible to these herbal alternatives than ATCC strain. The MIC values for the test Groups B and C were similar for both ATCC and clinical isolate (Table 2).

Table 1. Agar well diffusion / disc diffusion assay in triplicate.

\begin{tabular}{lcccccc}
\hline \multicolumn{1}{c}{ Test Group } & \multicolumn{2}{c}{ E faecalis (ATCC 29212) } & \multicolumn{2}{c}{ E. faecalis Clinical Isolate } \\
(Concentration) & Assay 1 & Assay 2 & Assay 3 & Assay 1 & Assay 2 & Assay 3 \\
\hline A (50 mg) & $6 \mathrm{~mm}$ & $6 \mathrm{~mm}$ & $6 \mathrm{~mm}$ & $6 \mathrm{~mm}$ & $6 \mathrm{~mm}$ & $6 \mathrm{~mm}$ \\
A (25 mg) & $6 \mathrm{~mm}$ & $6 \mathrm{~mm}$ & $6 \mathrm{~mm}$ & $6 \mathrm{~mm}$ & $6 \mathrm{~mm}$ & $6 \mathrm{~mm}$ \\
B (50 mg) & $25 \mathrm{~mm}$ & $24 \mathrm{~mm}$ & $25 \mathrm{~mm}$ & $25 \mathrm{~mm}$ & $24 \mathrm{~mm}$ & $25 \mathrm{~mm}$ \\
B (25 mg) & $20 \mathrm{~mm}$ & $20 \mathrm{~mm}$ & $20 \mathrm{~mm}$ & $20 \mathrm{~mm}$ & $20 \mathrm{~mm}$ & $20 \mathrm{~mm}$ \\
C (50 mg) & $18 \mathrm{~mm}$ & $17 \mathrm{~mm}$ & $18 \mathrm{~mm}$ & $21 \mathrm{~mm}$ & $20 \mathrm{~mm}$ & $21 \mathrm{~mm}$ \\
C (25 mg) & $12 \mathrm{~mm}$ & $12 \mathrm{~mm}$ & $12 \mathrm{~mm}$ & $18 \mathrm{~mm}$ & $16 \mathrm{~mm}$ & $18 \mathrm{~mm}$ \\
Vancomycin $(30 \mu \mathrm{g})$ & $21 \mathrm{~mm}$ & $21 \mathrm{~mm}$ & $21 \mathrm{~mm}$ & $21 \mathrm{~mm}$ & $21 \mathrm{~mm}$ & $21 \mathrm{~mm}$ \\
NaOCl $(5 \%)$ & $29 \mathrm{~mm}$ & $28 \mathrm{~mm}$ & $29 \mathrm{~mm}$ & $29 \mathrm{~mm}$ & $28 \mathrm{~mm}$ & $29 \mathrm{~mm}$ \\
Chlorhexidine $(2 \%)$ & $30 \mathrm{~mm}$ & $29 \mathrm{~mm}$ & $30 \mathrm{~mm}$ & $33 \mathrm{~mm}$ & $33 \mathrm{~mm}$ & $32 \mathrm{~mm}$ \\
\hline
\end{tabular}

Group A: Trigonella foenum; Group B: Terminalia chebula; Group C: Syzygium cumini.

Time kill curve (Figure 1) showed two log reductions for the test Group B after 30 mins of exposure and complete inhibition following 60 mins of exposure, while Group C showed two log reduction and one $\log$ reduction after $60 \mathrm{mins}$ of exposure on ATCC strain and clinical isolate, 
respectively. SEM analysis of control sample demonstrates matured biofilm structure of E. faecalis (Figure 2A). Smear Layer has been effectively removed by $T$. chebula seed extracts (Figure 2B), while the seed extracts of $S$. cumini failed to remove the smear layer (Figure $2 \mathrm{C}$ ).

Table 2. Broth dilution assay.

\begin{tabular}{lcc}
\hline \multicolumn{1}{c}{ Groups } & \multicolumn{2}{c}{ Minimum Inhibitory Concentration } \\
& E.faecalis (ATCC 29212) & E.faecalis (Clinical Isolate) \\
\hline $\mathrm{B}$ & $3.12 \mathrm{mg} / \mathrm{mL}$ & $6.25 \mathrm{mg} / \mathrm{mL}$ \\
$\mathrm{C}$ & $3.12 \mathrm{mg} / \mathrm{mL}$ & $6.25 \mathrm{mg} / \mathrm{mL}$ \\
$\mathrm{NaOCl}(5 \%)$ & $0.5 \%$ & $0.5 \%$ \\
Chlorhexidine (2\%) & $0.002 \%$ & $0.002 \%$ \\
\hline Group B: Terminalia chebula ; Group C: Syzygium cumini.
\end{tabular}

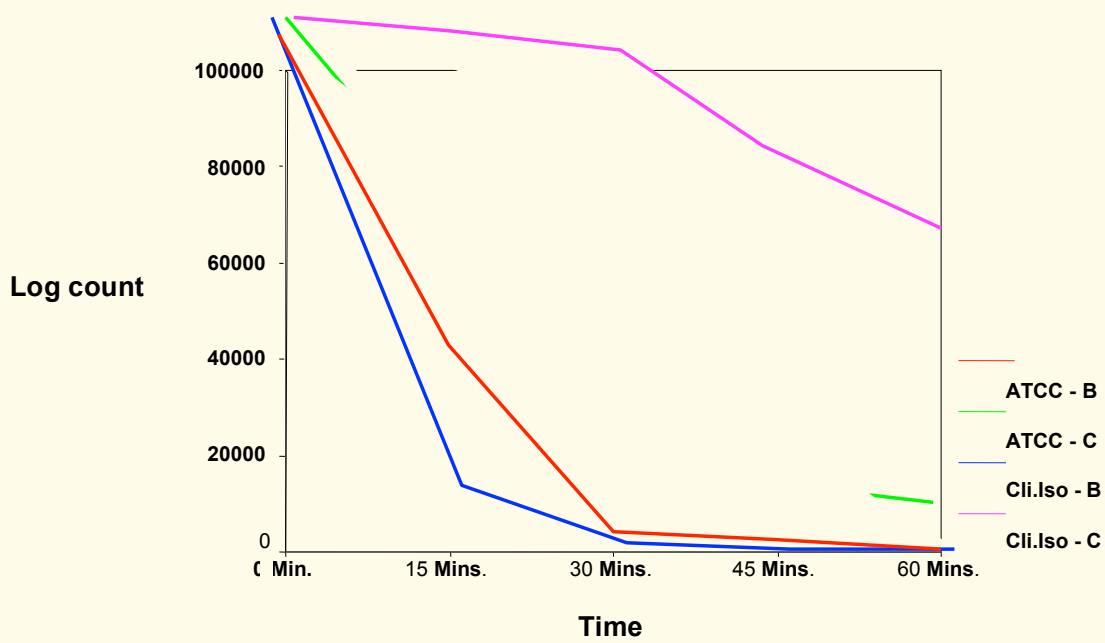

Figure 1. Time kill curve. ATTC-B: Clinical isolate B-two log reductions after 30 mins of exposure and complete inhibition following $60 \mathrm{mins}$ of exposure. ATTC-C: Clinical isolate C-two log reduction and one $\log$ reduction after $60 \mathrm{mins}$ of exposure. The curves within the box represents the E. faecalis colony forming units count up to $1 \times 10^{5}$. The curves displayed outside the box refers the colony forming units count beyond $1 \times 10^{5}$.
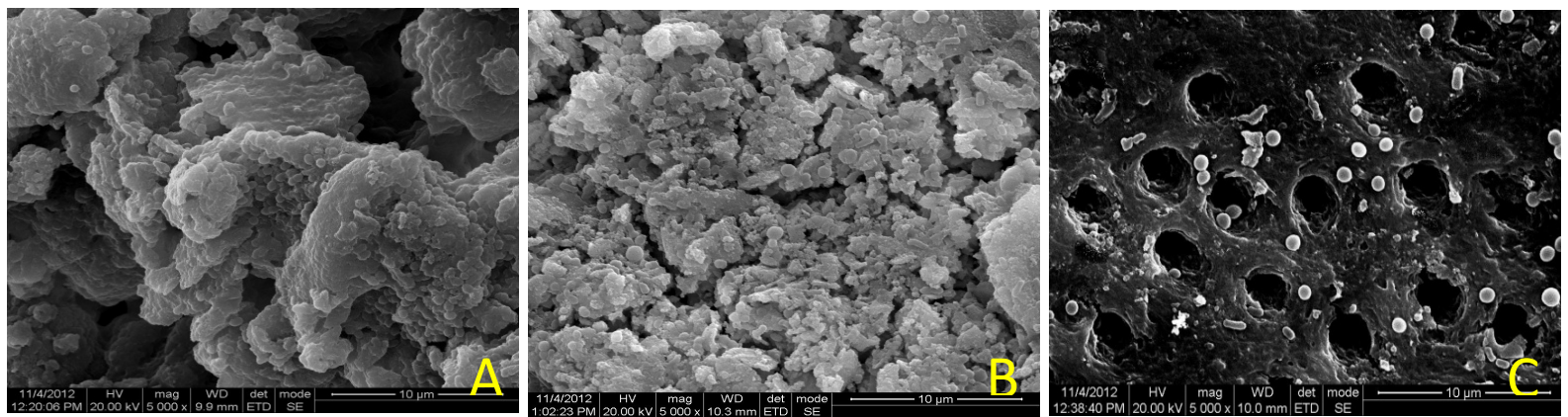

Figure 2. Scanning electron microscopy of root canal surface. A) Control: 6-week E. faecalis biofilm without herbal treatment; B) Absence of smear layer removal by seed extracts of $S$. cumini; C) Smear layer removal by seed extracts of $T$. chebula.

\section{Discussion}

The constant increase in antibiotic-resistant strains and adverse effects caused by many synthetic drugs has impelled researchers to look for plant products, which may be safe and biocompatible. The 
efficacy of antibiotics on planktonic counterparts by itself is challenging these days due to the high-level resistance expressed by various bacterial strains. Physically when it comes to eradicating biofilm, it is even more difficult to treat them as the biofilm forming community can be 1500 times more antibioticresistant than free-floating bacteria [24].

The microorganisms present in the oral cavity are the prime source of biofilm formation within the root canal system. The anatomical structure of the root canal system provides protection to microorganisms. Facultative or strict anaerobes are more frequently encountered than aerobic bacteria. Among various facultative anaerobes, Enterococcus faecalis is found to be frequently associated with posttreatment endodontic infections [25]. In the present study, a six-week-old biofilm was assayed against the herbal alternatives as bacteria-induced dissolution of the dentine surface and the ability of E. faecalis to form calcified biofilm on root canal dentine may be a factor that contributes to their persistence after endodontic treatment [26].

An effective root canal irrigant should possess tissue dissolving, antibacterial and smear layer removal properties. Except for $\mathrm{NaOCl}$, none of the conventional irrigants possess all these three properties. Furthermore, conventional irrigants proven to be an effective antibacterial agent may cause detrimental effects on vital tissues [27].

In developing countries, plant products play a vital role as therapeutic remedies in primary healthcare. The recognized Indian systems of medicine like Ayurveda and Siddha use herbs in the formulations. As the plant products are considered to be less toxic with the absence of side effects, the present study was designed to evaluate the efficacy of the three herbal products against E. faecalis dentinal biofilm.

The methanolic extracts of $T$. chebula seeds showed a very high zone of inhibition compared to $T$. foenum and S. cumini. The inhibition was comparable to $\mathrm{NaOCl}(5 \%)$ and $2 \%$ chlorhexidine. T. chebula inhibition zone was higher than vancomycin. The methanolic extracts of the seeds of S. cumini also showed moderate activity when compared with vancomycin, while the zone of inhibition was low when compared to $\mathrm{NaOCl}(5 \%)$ and $2 \%$ chlorhexidine. The extracts of $T$. foenum seeds did not possess antibacterial activity against E. faecalis. In the present study, E. faecalis clinical isolate was more susceptible then the ATCC strain against methanolic extracts of S. cumini seeds and $2 \%$ chlorhexidine.

As no activity was observed for $T$. foenum micro broth dilution assay was not performed. The minimum inhibitory concentration was determined for all the other groups. In spite of the low zone of inhibition by S. cumini seed extract, the MIC was similar for both T. chebula and S. cumini. This low zone of inhibition could be attributed to improper diffusion of the extracts.

In the time-kill assay, extracts of $T$. chebula showed two log reductions after 45 minutes and four $\log$ reductions following 60 minutes exposure. The four-log reduction would have occurred between 45 and 60 minutes. Complete inhibition was observed after 45 and 60 minutes for E. faecalis clinical isolate and ATCC, respectively. Only one $\log$ reduction was observed for the extracts of $S$. cumini even after 60 minutes, while complete inhibition was observed after 18 hours of incubation. The tooth samples with sixweek biofilm treated against $T$. chebula and S. cumini extracts were analyzed by SEM to assess the smear layer removal. The smear layer removal was assessed after the interaction of the test solutions for 60 minutes. T. chebula seed extracts removed the smear layer efficiently. The smear layer removal capacity of T. chebula may be attributed to the phytochemical substance chebulinic acid present in them. Smear layer removal was not observed for $S$. cumini seed extracts. 


\section{Conclusion}

The extracts of $T$. chebula seeds may be replaced for conventional irrigants due to its antibacterial properties and smear layer removing ability with least erosion on dentinal surface. The extracts of $S$. cumini may be used as an intracanal medicament as complete inhibition of six weeks old E. faecalis dentinal biofilm was observed after 18 hours of treatment.

\section{Authors' Contributions}

\begin{tabular}{|c|c|c|}
\hline AS & (iD) $0000-0003-2855-6636$ & Conceptualization, Methodology and Writing - Original Draft Preparation. \\
\hline KR & 0000-0001-9143-352X & Investigation and Formal Analysis. \\
\hline KM & 0000-0003-2753-9092 & $\begin{array}{l}\text { Investigation, Formal Analysis, Writing - Original Draft Preparation and Writing } \\
\text { - Review and Editing. }\end{array}$ \\
\hline KP & (D) $0000-0002-0790-1464$ & Investigation and Formal Analysis. \\
\hline PV & (iD) $0000-0003-2866-5349$ & Conceptualization, Methodology and Writing - Original Draft Preparation. \\
\hline
\end{tabular}

\section{Financial Support}

None.

\section{Conflict of Interest}

The authors declare no conflicts of interest.

\section{References}

[1] Stuart CH, Schwartz SA, Beeson TJ, Owatz CB. Enterococcus faecalis: Its role in root canal treatment failure and current concepts in retreatment. J Endod 2006; 32(2):93-8. https://doi.org/10.1016/j.joen.2005.10.049

[2] Arias-Moliz MT, Ferrer-Luque CM, González-Rodríguez MP, Valderrama MJ, Baca P. Eradication of Enterococcus faecalis biofilms by cetrimide and chlorhexidine. J Endod 2010; 36(1):87-90. https://doi.org/10.1016/j.joen.2009.10.013

[3] Portenier I, Waltimo TMT, Haapasalo M. Enterococcus faecalis - the root canal survivor and 'star' in posttreatment disease. Endod Top 2003; 6(1):135-59. https://doi.org/10.1111/j.1601-1546.2003.00040.x

[4] Kayaoglu G, Orstavik D. Virulence factors of Enterococcus faecalis: relationship to endodontic disease. Crit Rev Oral Biol Med 2004; 15(5):308-20. https://doi.org/10.1177/154411130401500506

[5] Bryce G1, O'Donnell D, Ready D, Ng YL, Pratten J, Gulabivala K. Contemporary root canal irrigants are able to disrupt and eradicate single- and dual-species biofilms. J Endod 2009; 35(9):1243-8. https://doi.org/10.1016/j.joen.2009.05.034

[6] Peters OA, Schönenberger K, Laib A. Effects of four Ni-Ti preparation techniques on root canal geometry assessed by micro computed tomography. Int Endod J 2001; 34(3):22 1-30. https://doi.org/10.1046/j.1365-2591.2001.00373.x

[7] Torabinejad M1, Handysides R, Khademi AA, Bakland LK. Clinical implications of the smear layer in endodontics: a review. Oral Surg Oral Med Oral Pathol Oral Radiol Endod 2002; 94(6):658-66. https://doi.org/10.1067/moe.2002.128962

[8] de Gregorio C, Estevez R, Cisneros R, Paranjpe A, Cohenca N. Efficacy of different irrigation and activation systems on the penetration of sodium hypochlorite into simulated lateral canals and up to working length: an in vitro study. J Endod 2010; 36(7):1216-21. https://doi.org/10.1016/j.joen.2010.02.019

[9] Williamson AE, Cardon JW, Drake DR. Antimicrobial susceptibility of monoculture biofilms of a clinical isolate of Enterococcus faecalis. J Endod 2009; 35(1):95-7. https://doi.org/10.1016/j.joen.2008.09.004

[10] Neglia R, Ardizzoni A, Giardino L, Ambu E, Grazi S, Calignano S, et al. Comparative in vitro and ex vivo studies on the bactericidal activity of Tetraclean, a new generation endodontic irrigant, and sodium hypochlorite. New Microbiol 2008; $31(1): 57-65$.

[11] Ehrich DG, Brian JD Jr, Walker WA. Sodium hypochlorite accident: inadvertent injection into the maxillary sinus. J Endod 1993; 19(4):180-2. https://doi.org/10.1016/So099-2399(06)80684-9

[12] Becking AG. Complication in the use of sodium hypochlorite during endodontic therapy. Oral Surg Oral Med Oral Pathol 1991; 71:346-8. 
[13] Mohammadi Z, Abbott PV. The properties and applications of chlorhexidine in endodontics. Int Endod J 2009; 42(4):288-302. https://doi.org/10.1111/j.1365-2591.2008.01540.x

[14] Faria G, Celes MR, De Rossi A, Silva LA, Silva JS, Rossi MA. Evaluation of chlorhexidine toxicity injected in the paw of mice and added to cultured L929 fibroblasts. J Endod 2007; 33(6):715-22. https://doi.org/10.1016/j.joen.2006.12.023

[15] Flammang AM, Cifone MA, Erexson GL, Stankowski LF Jr. Genotoxicity testing of a fenugreek extract. Food Chem Toxicol 2004; 42(11):1769-75. https://doi.org/10.1016/j.fct.2004.07.003

[16] Nadkarni AK. Indian Materia Medica. Bombay: Popular Book Depot; 1976.

[17] Gottfried SF. The raison of secondary plant substances. Science 2007; 129(3361):1466-70.

[18] Meshram GA, Yadav SS, Shinde D, Patil B, Singh D. Antibacterial study and effect of ethanolic extracts of Syzygium cumini seeds powder on glucoamylase in vitro. Pharm Sci Res 2011;3(2):1060-3.

[19] Chopra R, Nayar S, Chopra I. Glossary of Indian Medicinal Plant. $3^{\text {rd }}$ ed. New Delhi: Council of Scientific and Industrial Research; 1956. 249pp.

[20] Fabry W, Okemo PO, Ansorg R. Antibacterial activity of East African medicinal plants. J Ethnopharmacol 1998; 60(1):79-84. https://doi.org/10.1016/s0378-87411(97)00128-1

[21] Aneja KR, Joshi R. Evaluation of antimicrobial properties of fruit extracts of Terminalia chebula against dental caries pathogens. Jundishapur J Microbio 2009; 2(3):105-11.

[22] Facklam RR, Carvalho MG, Teixeira LM. History, Taxonomy, Biochemical Characteristics, and Antibiotic Susceptibility Testing of Enterococci. In: Gilmore MS (Editor). The Enterococci: Pathogenesis, Molecular Biology, and Antibiotic Resistance. Washington: ASM Press; 2002. p. 1-54.

[23] Prabhakar J, Senthilkumar M, Priya MS, Mahalakshmi K, Sehgal PK, Sukumaran VG. Evaluation of antimicrobial efficacy of herbal alternatives (Triphala and green tea polyphenols), MTAD, and 5\% sodium hypochlorite against Enterococcus faecalis biofilm formed on tooth substrate: An in vitro study. J Endod 2010; 36(1):83-6. https://doi.org/10.1016/j.joen.2009.09.040

[24] Socransky SS, Haffajee AD. Dental biofilms: difficult therapeutic targets. Periodontology 2000 2002; 28(1):1255. https://doi.org/10.1034/j.1600-0757.2002.280102.x

[25] Mala K. Endodontic biofilms - their formation and eradication: a review. J Nepal Dent Assoc 2011; 1(2):54-8.

[26] Kishen A, George S, Kumar R. Enterococcus faecalis-mediated biomineralized biofilm formation on root canal dentine in vitro. J Biomed Mater Res A 2006; 77(2):406-15. https://doi.org/10.1002/jbm.a.30622

[27] Pashley EL, Birdsong NL, Bowman K, Pashley DH. Cytotoxic effects of NaOCl on vital tissue. J Endod 1985; 11(12):525-8. https://doi.org/10.1016/Soo99-2399(85)80197-7 